\title{
THE TRICHO-RHINO-PHALANGEAL SYNDROME
}

\author{
A REPORT OF 14 CASES IN 7 KINDREDS \\ C. J. HOWELL, RUTH WYNNE-DAVIES \\ From Harlow Wood Orthopaedic Hospital, Mansfield
}

\begin{abstract}
Tricho-rhino-phalangeal syndrome is probably not so much uncommon as unrecognised. Its significance to orthopaedic surgeons, apart from the functionally unimportant minor finger deformities, lies in its mimicking both Perthes' disease and diaphyseal aclasis. The 14 cases analysed in this paper illustrate the wide range of clinical variation.
\end{abstract}

This syndrome is one of autosomal dominant inheritance, and was first described by Giedion (1966) who characterised it by sparse and slowly-growing hair, a long pear-shaped nose with a bulbous tip, and finger deformities. The latter were due to cone-shaped epiphyses with irregular premature fusion, resulting in clinodactyly, brachydactyly and in some cases finger contractures. The condition may have been recognised first by van der Werff Ten Bosch (1959) but he did not describe it in any detail or recognise the heritable characteristics.

Since these papers, many more patients have been reported and other features of the syndrome have been noted in some, but not all, cases. Perthes'-like changes have been seen in the hip, and multiple exostoses similar to those in diaphyseal aclasis have been reported (Beals 1973; Giedion et al. 1973; Weaver, Cohen and Smith 1974; Sugiura et al. 1976; Sugiura 1978; Frias et al. 1979). Langer (1969) and Hall et al. (1974) described a variant with mental retardation, microcephaly, skin and joint laxity and multiple exostoses, currently called the trichorhino-phalangeal syndrome Type II, which has autosomal recessive inheritance and appears to be extremely rare.

We have reviewed 14 patients from 7 families with the Type I syndrome, and have summarised the features and outlined the clinical significance of the deformities.

\section{MATERIAL AND METHOD}

Five index patients and six affected relatives had attended Harlow Wood Orthopaedic Hospital, Nottinghamshire, one index patient and her affected son were from St Thomas' Hospital, London, and one case, with

C. J. Howell, FRCS, Consultant Orthopaedic Surgeon City Hospital, Hucknall Road, Nottingham NG5 IPE, England. R. Wynne-Davies, FRCS

2 Dale Close, St Ebbe's, Oxford OXI ITU, England. Requests for reprints should be sent to $\mathrm{MrC}$. J. Howell.

(C) 1986 British Editorial Society of Bone and Joint Surgery $0301-620 \mathrm{X} / 86 / 2025 \$ 2.00$ less complete information, was from abroad. The first six index patients and all their affected relatives were reassessed for the purpose of this paper: genetic, clinical and radiographic data were collected and note was made of their current clinical problems.

\section{RESULTS}

The patients' ages ranged from 13 months to 51 years, and all but one had been observed over a period of between three and seven years.

Inheritance. In five of the index patients the disease was probably of autosomal dominant inheritance since the same disorder was apparent amongst their parents, siblings and children. In these families there were two affected fathers, one and possibly another affected mother; one of two brothers, and two, possibly three, of 11 sisters had the disorder, as had one of two sons. The other two index patients were sporadic cases but not apparently, as is often the case with new dominant mutations, due to a paternal age effect, since the fathers' ages were 31 and 27 years.

Sex ratio. This was equal; three index patients were male and four female; there were four males and three (possibly five) females among the affected relatives.

Presenting feature. Eight of the patients had presented with minor hand deformities, at or over the age of four years. Two presented with hip pain and limitation of movement, aged 10 and 12 years; one presented with lower limb exostoses at four years, the other three were first diagnosed because their facial appearance was similar to that of relatives known to be affected.

Intelligence. This was normal in all cases.

Stature. Short stature and body disproportion was not found to be a marked feature, although no individual measured more than the 50th centile. Only one of the seven males had an adult height below the third centile $(151 \mathrm{~cm})$; of the seven females, two were on the third centile, and a third, at only 13 years of age, was below it $(126.5 \mathrm{~cm})$. Both patients with height below the third cen- 


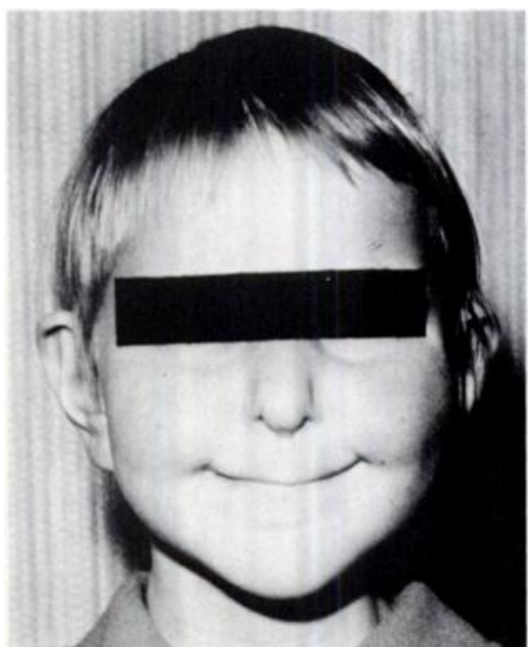

Fig. 1

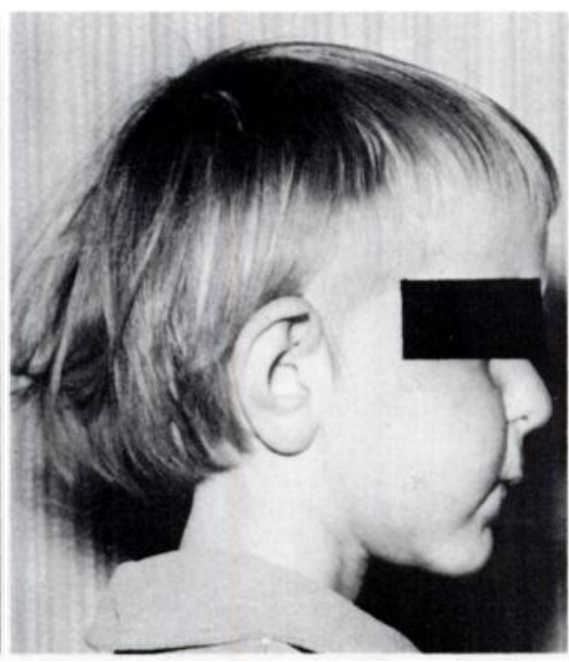

Fig. 2

A girl aged 7 years, showing the fine hair. wide mouth. long philtrum and bulbous tip of the nose which are characteristic of the tricho-rhino-phalangeal syndrome.

tile were severely affected by the disease. The mean span was very slightly reduced, probably because of shortened fingers; the ratio of head-to-pubis and pubis-to-heel distances was normal.

Facial appearance. The "rhino-" part of the syndrome is shown by a pear-shaped nose with a bulbous tip and a long philtrum, and this was present in 13 of the 14 patients (Figs 1 and 2). In the more severe cases the mouth was unusually wide, and one of these patients had a high-arched palate. The teeth appeared to be normal in most cases, but in one patient there was marked overcrowding, and another had retained her deciduous teeth until the age of nine years. The only other facial abnormality noted was that one patient had pupils of unequal sizes.

Hair. All patients had the typically fine, sparse hair, sometimes of poor quality, breaking and pulling out easily. Most referred to absent or very slow growth, and rarely needed a hair cut. One patient had no hair at all until the age of two years, one boy was balding at 16 years of age, and another boy had a crew cut at the age of 12 after which his hair never grew again.

Hands. Deformity or less than perfect function of the hands was the commonest presenting sign. The only patient in this series with normal hands was an infant aged $2 \frac{1}{2}$ years, who may yet develop deformities. The patients' hands were irregularly short and stubby, with clinodactyly of at least one finger (most commonly the index), and sometimes of all four fingers. Angulation was usually to the ulnar side, but could be radial, or to both radial and ulnar sides at different levels in the same finger. One or more metacarpals were short in six patients. Radiographs showed coning of affected epiphyses during growth, variably of the proximal, middle or terminal phalanges, and clearly their irregular growth and premature fusion was the cause of the clinodactyly and brachydactyly (Figs 3 and 4).
Feet. These were affected in the same manner as the hands, but to a lesser extent and in only 5 of the 14 patients.

Hips. There were problems in one or both hips in 6 of the 14 patients. Two had quite severe pain, and all six showed some limitation of rotation and abduction; one had a waddling gait. Radiographic changes have been likened to those of Perthes' disease, with flattening and fragmentation of the capital femoral epiphyses and premature osteoarthritis. Unusually for a skeletal dysplasia, the defect in this syndrome may be unilateral or

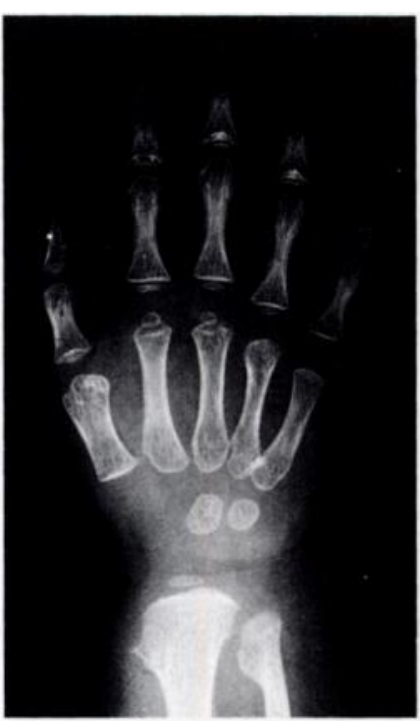

Fig. 3

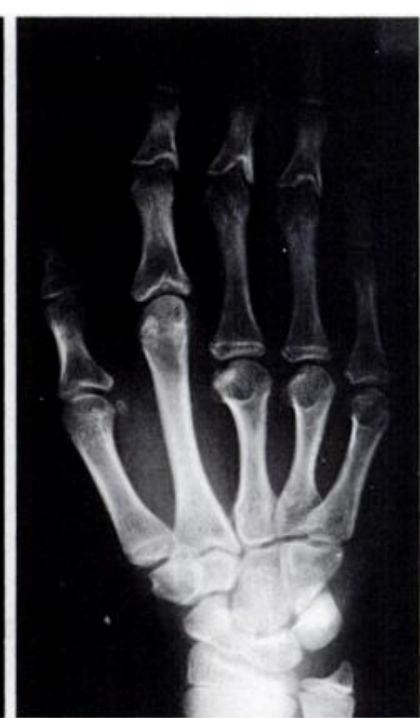

Fig. 4
Figure 3-Hand of a girl aged $3 \frac{1}{2}$ years. An early exostosis is seen at the lower ends of the radius and ulna, and there is coning of the epiphyses at the bases of the middle phalanges of the index, middle and ring fingers. Figure $4-H$ and of a girl aged $14 !$ years. The third, fourth and fifth metacarpals are short, as is the proximal phalanx of the index finger. Coned epiphyses are seen at the bases of the middle phalanges of the index, middle and ring fingers with slight ulnar clinodactyly. 


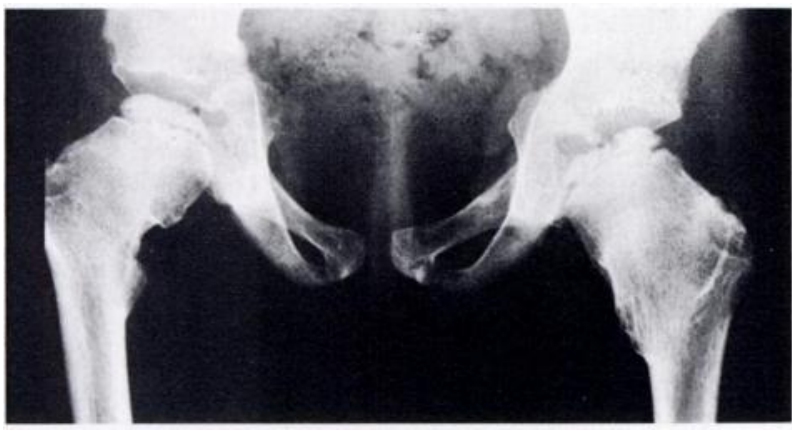

Fig. 5

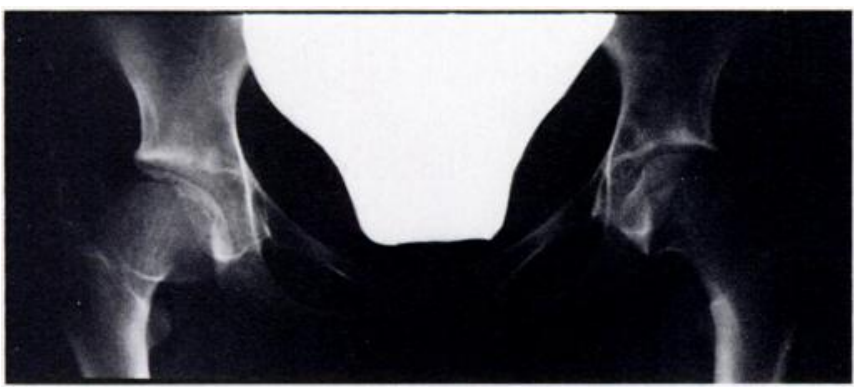

Fig. 7

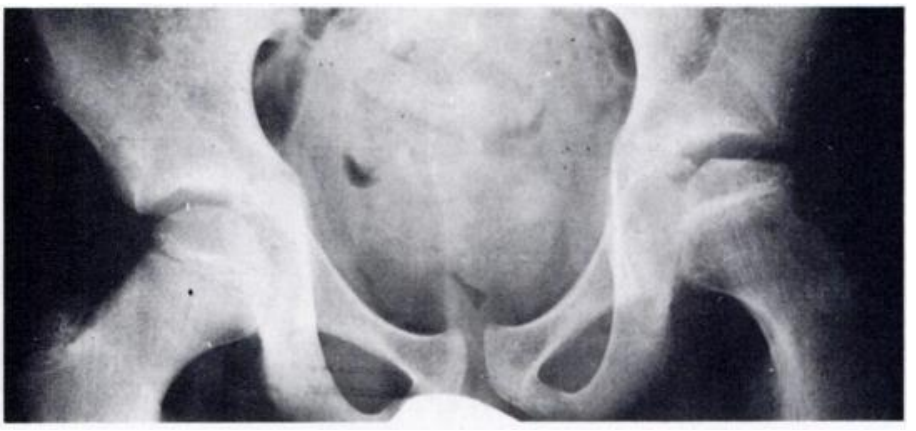

Fig. 6

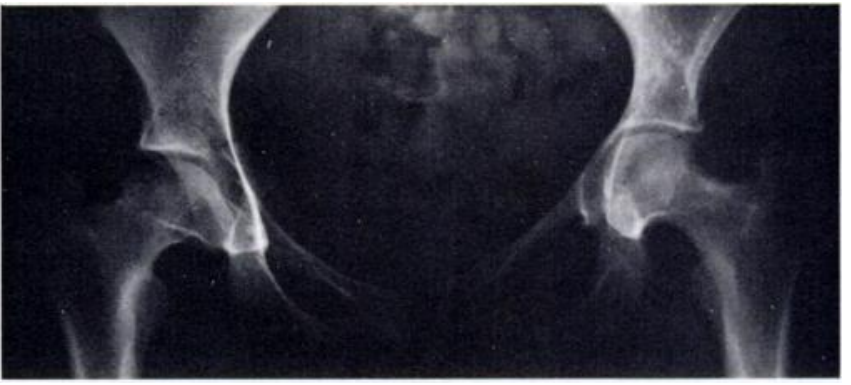

Fig. 8

Radiographs of the pelvis to show hips affected by the syndrome. Figure 5-Girl aged 7 years. The hips show bilateral sessile exostoses on the upper femora. The capital femoral epiphyses are irregular, flattened and fragmented, but do not show the areas of increased density characteristic of Perthes' disease. Figure 6-Boy aged 10 years who presented with hip pain. Only the left capital femoral epiphysis is affected, with irregularity and some flattening. Figure 7-Girl aged 17 years who is symptomless but has some limitation of movement. The right hip only has been affected by an epiphyseal disturbance during growth. Figure 8-Woman aged 27 years. The right hip had an epiphyseal disorder during growth, but is now free of symptoms. The left hip is painful, with limited mobility, and shows mild protrusio acetabuli.

bilateral, and may be asymmetrical (Figs 5 to 8 ). It is possible that a seventh patient may develop a hip disorder; he is now $2 \frac{1}{2}$ years old and the capital femoral epi-

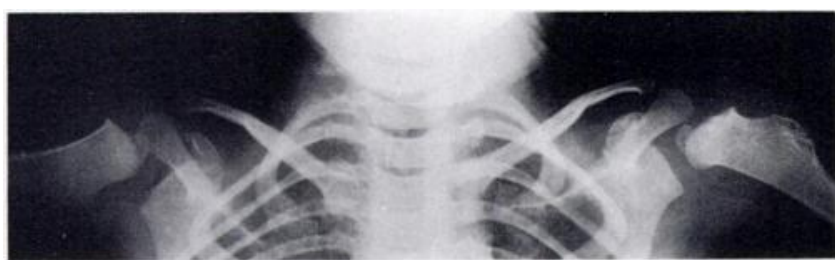

Fig. 9

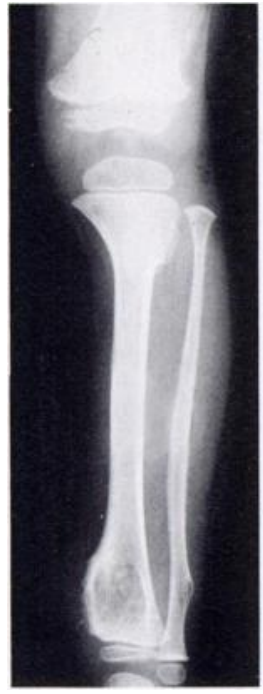

Radiographs of a girl aged 7 years. Figure 9 Exostoses are seen on each upper humerus. Figure 10-Exostoses are present on the lower femur, at both ends of the tibia and at the lower end of the fibula.

Fig. 10 physes have only just ossified. A delay such as this is invariable in cases of multiple epiphyseal dysplasia.

Long bones. The long bones, other than those of the hands and feet, were normal in the 12 patients without exostoses. One patient had small exostoses on the heads of the second, third and fourth metacarpals. The more seriously involved patient had exostoses on all long bones of both upper and lower limbs (Figs 9 and 10). These presented at the age of four years at the wrist and ankle and had developed at both ends of all long bones by the age of 13 years; at the knee they were associated with deformity.

Spine. One infant who had a congenital tracheooesophageal fistula, also had congenital vertebral anomalies, with fusions in the mid-thoracic spine and a lumbosacral hemivertebra. One other patient had a mild right idiopathic thoracic scoliosis.

Skull and chest. These were normal in all patients.

Associated anomalies. Additional developmental defects found in these patients included three instances of upper limb joint laxity, and one case each of tracheooesophageal fistula, unilateral hydro-ureter, pectus excavatum and congenital sternoclavicular dislocation.

Progress and complications. For most patients the problems were cosmetic rather than functional. Some had limitation of finger movement and difficulty in wearing rings. The hip disorder was potentially the most serious aspect and three patients, aged 10,24 and 41 years, complained of pain. This had so far been managed by con- 
servative measures, but it would appear that premature osteoarthritis was developing. Malalignment of the lower limbs in the severely affected girl with multiple exostoses will probably require corrective operations.

\section{DISCUSSION}

This study confirms previous reports on the clinical features of the syndrome and its autosomal dominant inheritance, which gives a $50 \%$ risk that affected individuals will pass the disorder on to their own children. Our series included no example of the so-called Type II tricho-rhino-phalangeal syndrome, with microcephaly, mental retardation, exostoses and joint laxity, although patients with joint laxity or with exostoses were seen without any of the other Type II features.

Differential diagnosis. A feature of the syndrome is the wide range of severity, from minor hand defects only, to an undersized child with multiple exostoses, limb malalignment and growth disturbance of the capital femoral epiphyses. In one of our patients the hand defects had been diagnosed as missed fractures and in another as Still's disease, although there is no real similarity. Coneshaped phalangeal epiphyses are found in many other skeletal dysplasias and are also said to occur in about $5 \%$ of otherwise normal children.

A more likely cause of confusion is diaphyseal aclasis. This is also of dominant inheritance, but there is no separate epiphyseal growth disturbance in the digits. The characteristic hair and facial appearance of the trichorhino-phalangeal syndrome should make the diagnosis clear. In those cases with an epiphyseal growth disturbance in one or both hips, Perthes' disease must be considered, but in the tricho-rhino-phalangeal syndrome radiographic appearances do not go through periods of deterioration and then of improvement, there are no areas of increased density in the capital femoral epiphyses, the metaphyses are not involved, and, again, changes in the hands, hair and face should make the diagnosis clear. Multiple epiphyseal dysplasia affecting the hips is very similar, but, unlike the tricho-rhinophalangeal syndrome, would always be bilateral. Other joints are frequently affected; the acetabulum is likely to show a scalloped outline and the hands, hair and face will not show the characteristic changes.

We are grateful to the orthopaedic surgeons at Harlow Orthopaedic Hospital and St Thomas' Hospital for referring these patients to the Skeletal Dysplasia Clinic, and for access to the clinical material.

\section{REFERFNCES}

Beals RK. Tricho-rhino-phalangeal dysplasia: report of a kindred J Bone Joint Surg $[\mathrm{Am}]$ 1973:55 A:821 6 .

Frias JL, Felman AH, Garnica AD, Wallace SE. Variable expressivity in the tricho-rhino-phalangeal syndrome Type I. Birth Defects $1979 ; 15(5$ B $): 36172$.

Giedion A. Das tricho-rhino-phalangeale Syndrom. Helv Paediatr Acta 1966:21:475:85.

Giedion A, Burdea M, Fruchter Z, Meloni T, Trosc V. Autosomaldominant transmission of the tricho-rhino-phalangeal syndrome: report of 4 unrelated families, review of 60 cases. Helv Paediatr Acta 1973:28:249 59 .

Hall BD, Langer LO, Giedion A, et al. Langer Giedion syndrome. Birth Defects 1974:10(12):147 64

Langer LO. The thoracic pelvic phalangeal dystrophy. Birth Defects 1969:5(4):55 64 .

Sugiura Y. Tricho-rhino-phalangeal syndrome associated with Perthesdisease-like bone change and spondylolisthesis. Jinrui Idengaku Zasshi 1978:23:23 30.

Sugiura Y, Shionoya M, Inoue T, Tsuruta T. Tricho-rhino-phalangeal syndrome: report on three unrelated families. Jpn J Hum Genet 1976:21:1322.

van der Werff Ten Bosch JJ. The syndrome of brachymetacarpal dwarfism ("pseudo-pseudohypoparathyroidism") with and without gonadal dysgenesis. Lancet 1959:i:69 71 .

Weaver DD, Cohen MM, Smith DW. The tricho-rhino-phalangeal syndrome. J Med Genet 1974:11:312 4 